\title{
In Vitro Production of Porcine Embryos: A Descriptive Approach, Limitations and Applications
}

\author{
Valadão L*, Silva H, Kajabova S and Moreira da Silva F \\ Department of Animal Reproduction, University of the Azores, Portugal
}

*Corresponding author: Valadão L, Department of Animal Reproduction, University of the Azores, Faculty of Agrarian Sciences and Environment, CITA-A (Research Centre for Agricultural and Environmental Sciences and Technology of the Azores), Angora do Heroismo 9700-042, Portugal

\begin{tabular}{|c|c|}
\hline ARTICLE INFO & ABSTRACT \\
\hline Received: 貲 February 25, 2020 & \multirow{3}{*}{$\begin{array}{l}\text { The in vitro production of porcine embryos aims to potentiate oocytes, maximize } \\
\text { the use of breeders, create high value and viable embryos for transfer to receivers. This } \\
\text { biotechnology involves different steps related to the manipulation of female gametes } \\
\text { such ovarian harvesting, follicular puncture, oocyte maturation, oocyte fertilization and } \\
\text { embryo culture. Difficulties such as reaching cytoplasmic maturation in the oocytes, } \\
\text { high polyspermy ratio as well as the low capacity in embryonic development until the } \\
\text { blastocyst stage, and further transfer to synchronized sows are the main reasons why } \\
\text { this technique is not yet very popular. However, there has been an effort by the scientific } \\
\text { community to improve this technique to move from an experimental level to a field tool. }\end{array}$} \\
\hline Published: March 05, 2020 & \\
\hline $\begin{array}{l}\text { Citation: Valadão L, Silva H, Kajabova S and } \\
\text { Moreira da Silva F. In Vitro Production of } \\
\text { Porcine Embryos: A Descriptive Approach, } \\
\text { Limitations and Applications. Biomed J Sci \& } \\
\text { Tech Res 26(2)-2020. BJSTR. MS.ID.004337. }\end{array}$ & \\
\hline
\end{tabular}

Keywords: In Vitro Production of Porcine Embryos; In Vitro Fertilization; Polyspermy

\section{Introduction}

Forty years ago, procedures for heat synchronization and artificial insemination were still being developed. Besides from 1980 on, the technique of in vitro production of bovine and ovine embryos began to be used in the field, only from 1990s in vitro production of porcine embryos did not have acceptable results. Conforming to [2], pigs account for about $40 \%$ of global meat consumption [1]. On the developed and developing countries, a sustainable supply of pork requires faster production for greater feed conversion efficiency, disease resistance and fertility. Thus, the in vitro fertilization, and further embryonic development can be a great advantage in different ways: in vitro produced embryos from selected gametes of high genetic value are an excellent resource for enhancing food production being also an useful resource for the development of biobanks to maintain biodiversity while preserving breeds [2]. In general, the steps for in vitro embryo production in swine are the same as for the other species, which is divided into different steps involving ovarian harvesting, follicular puncture, oocyte classification and maturation, oocyte fertilization and then embryo culture to the stage of blastocyst. Besides the scientific community has made efforts to make progress in this technique, the overall technology has limiting factors such as difficulty in achieving cytoplasmic maturation in oocytes, high polyspermy rate, low embryonic development capacity up to the blastocyst stage, and low rate of viable embryos $[3,4]$.

\section{Reproductive Physiology in Pigs}

The reproductive cycle of sows is quite peculiar, since they ovulate 15 to 30 oocytes in an estrous cycle, depending the quality of ovulating follicles on the follicular development process of the previous cycle [5]. The female pig's estrous cycle lasts between 18 and 24 days. It is divided into a follicular phase (5-7 days) whereas estrus lasts about 36 to $48 \mathrm{~h}$ in nulliparous and $48-72 \mathrm{~h}$ in sows and a luteal phase (13-15 days). The first phase begins with the corpus luteum regression and extends to ovulation [6]. At this step, LH stimulates estradiol secretion and instills the preovulatory growth wave (Figure 1). Then the corpora lutea form from the granulosa cells and the internal teak following ovulation of the follicles $[7,8]$. 


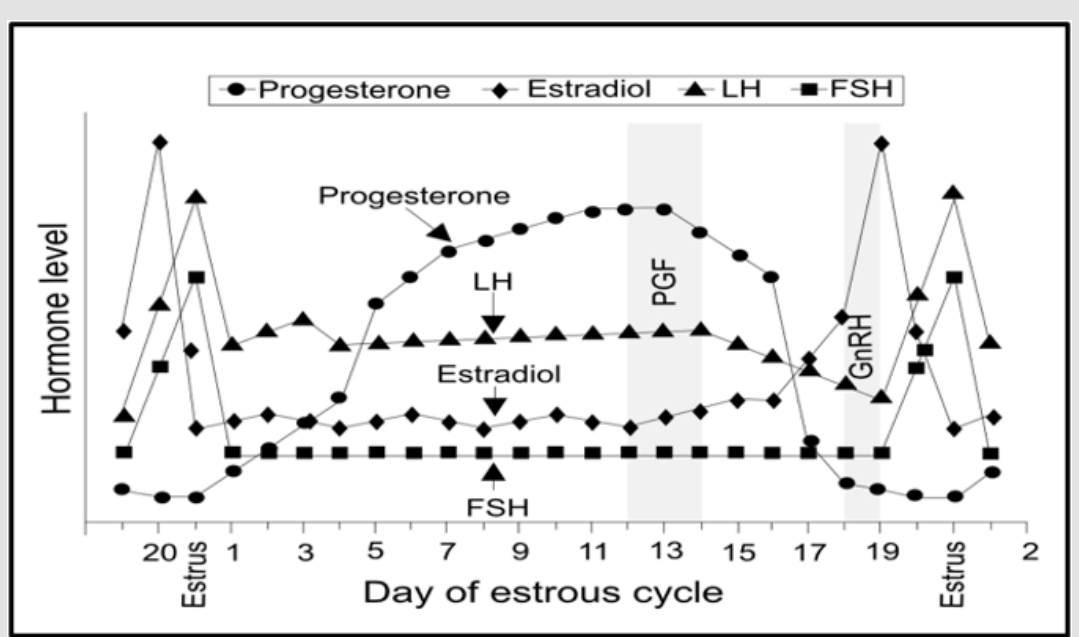

Figure 1: Estrous cycle: variation of reproductive hormones (LH- luteinizing hormone; FSH- follicle stimulating hormone; PGF- prostaglandin F-2 alpha; GnRH-gonadotropin releasing hormone) [8].

\section{In Vitro Embryo Production in Swine (PIVES)}

\section{Description of the Technique}

PIVES is a technique of assisted animal reproduction that also extends to pig farming. This biotechnology proposes different applications such as enhancing genetic progress by potentiating oocytes, or improving reproductive use, producing embryos with sexed semen, producing embryos in viable developmental stages to be transferred to recipients or cryopreserved genes and reduction in the number of animals to be used experimentally [4]. In vitro embryos are obtained through different techniques inherent to oocyte manipulation [3]. And these are ovarian collection at the local slaughterhouse and follicular puncture, oocyte maturation, oocyte fertilization and embryo culture (Figure 2).

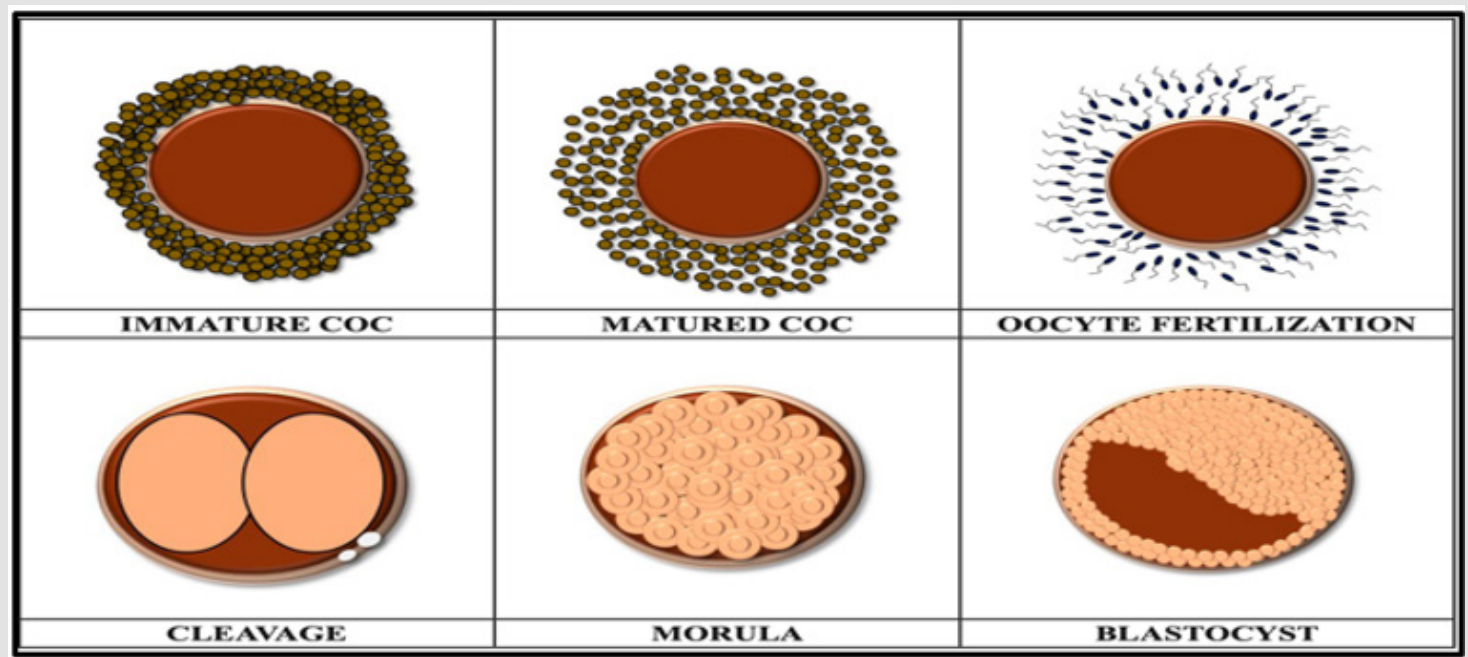

Figure 2: Schematization of the different stages of embryo development and before fertilization [3].

Ovarian collection and follicular puncture: The ovaries are collected at the local slaughterhouse after slaughter and transported to the laboratory in a cool box containing $0.9 \%$ saline containers at a temperature of $38{ }^{\circ} \mathrm{C}$ (where the ovaries are placed) with a maximum handling time of up to 2 hours after slaughter [9]. In the laboratory, the ovaries are washed twice with saline. Follicular puncture is then performed through an $18 \mathrm{~g}$ needle attached to a $10 \mathrm{ml}$ syringe, which allows the follicular fluid to pass into a conical tube preheated to $38{ }^{\circ} \mathrm{C}$. After 10 minutes, the precipitate is removed to a petri dish and kept in a plate heated to $38{ }^{\circ} \mathrm{C}[10]$. With the aid of a binocular magnifying glass the cumulus oocyte complexes (COCs) are washed in rinsing medium and evaluated according to morphological criteria and separated according to their quality [11]. And only quality 1 and quality 2 oocytes, which have four compact layers of cumulus cells, are used for in vitro maturation (Figure 3). 


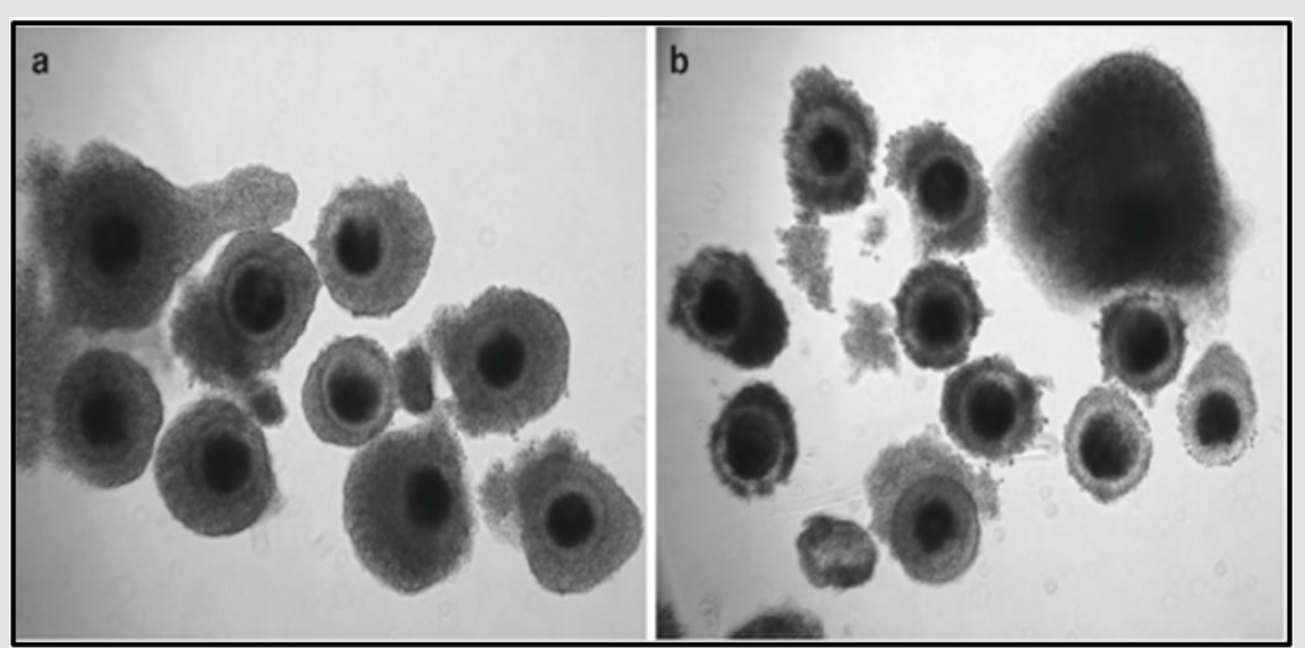

Figure 3: a) Good quality oocytes

b) Bad quality oocytes [12].

In Vitro Maturation (IVM): As reported by [12] COCs are placed in incubator at $38.5^{\circ} \mathrm{C}$, with $6 \% \mathrm{CO}_{2}$ and $100 \%$ humidity. Ongoing to fertilization they stay here for 42 to 44 hours. Oocyte maturation involves cellular changes that transform a non-progressing oocyte into an oocyte that is capable of withstanding fertilization and embryonic development events [13]. In vitro maturation involves two phases: nuclear maturation and cytoplasmic maturation. An important element for nuclear and cytoplasmic maturation of the oocyte is the cumulus cell layers surrounding the oocyte. Since these cells act as an intermediary between the oocyte and the follicular or culture environment. Intracellular communication between the oocyte and cumulus cells occurs through gap junctions, which are made by cumulus cells in direct contact with the zona pellucida, corona radiata cells [14].

Nuclear Maturation: According to [15], thesis nuclear maturation involves the progression of meiosis from prophase I to metaphase II. Nuclear maturation encompasses all changes in the distribution and organization of individual germinal vesicle organelles in metaphase II, which is activated automatically after removal of the oocyte from its follicle [16]. The onset of nuclear maturation occurs with the disappearance of the nucleolus and the condensation of chromosomes in the breakdown of the germ bladder.

Cytoplasmic Maturation: Cytoplasmic maturation involves the reorganization and storage of messenger RNA, proteins, and transcription factors that act on the overall process of maturation, fertilization, and early development of the embryo [17]. Cytoplasmic maturation of oocytes must occur so that a viable embryo can be produced [10]. According to [15], the metabolic changes that occur during cytoplasmic maturation of the oocyte are highly complex processes involving several events simultaneously, such as protein synthesis, molecular modifications, migration and reorganization of organelles in the cytoplasm.
In Vitro Fecundation (IVF): After maturation and prior to fertilization, oocytes are mechanically stripped. That is, cumulus cells are removed [9] by successive pipetting. According to [9] IVF involves various physiological processes of follicular maturation, fertilization and embryonic development that are achieved in the laboratory outside the animal's body. When the oocyte comes into contact with the sperm, a series of events culminate in the development of the embryo [4]. At sperm penetration the oocyte is in metaphase II. Activation of the sperm occurs, and the second meiotic division is finalized, passing through anaphase, telophase and expulsion of the polar corpuscle. There are many factors that affect the interaction of sperm with oocyte during IVF: culture medium, sperm to oocyte relationship, semen genesis (fresh or previously cryopreserved), these influence the penetration of sperm into the oocyte and polyspermy rate [18].

Sperm Capacitation: Prior to sperm capacitation, semen is centrifuged (2400g x 3min) [3] to separate the blood plasma. In contact with sperm, seminal plasma inhibits their potential. It is therefore essential for sperm capacitation to occur. In pigs, caffeine is used to induce semen capacitation [4]. Semen capacitation involves several functional modifications in the male primordial gametes to fertilize the oocyte. These include lipid membrane alterations, cholesterol loss, CAMP / PKA pathway activation, increased $\mathrm{Ca}^{2+}$ capacity, membrane potential hyperpolarization, and protein phosphorylation [13].

Acrosome Reaction: Conforming to [19] during the acrosomal reaction, the sperm plasma membrane and the acrosomal vesicle membrane fuse to form membrane vesicles. These are called acrosome reaction vesicles and contain signaling proteins and ion channels involved in the acrosome reaction. After the acrosome reaction, the exposed acrosome becomes in the sperm head and contains sperm enzymes. These facilitate sperm penetration through the zona pellucida. There is a fusion between the sperm 
head and the oocyte plasma membrane. However, only sperm that have undergone acrosome reaction can penetrate the zona pellucida and fuse with the plasma membrane [20].

\section{Embryos Culture}

Embryo culture is the last stage of in vitro embryo production. Here the zygote undergoes cleavage and evolves to morula and later to blastocyst (Figure 4).

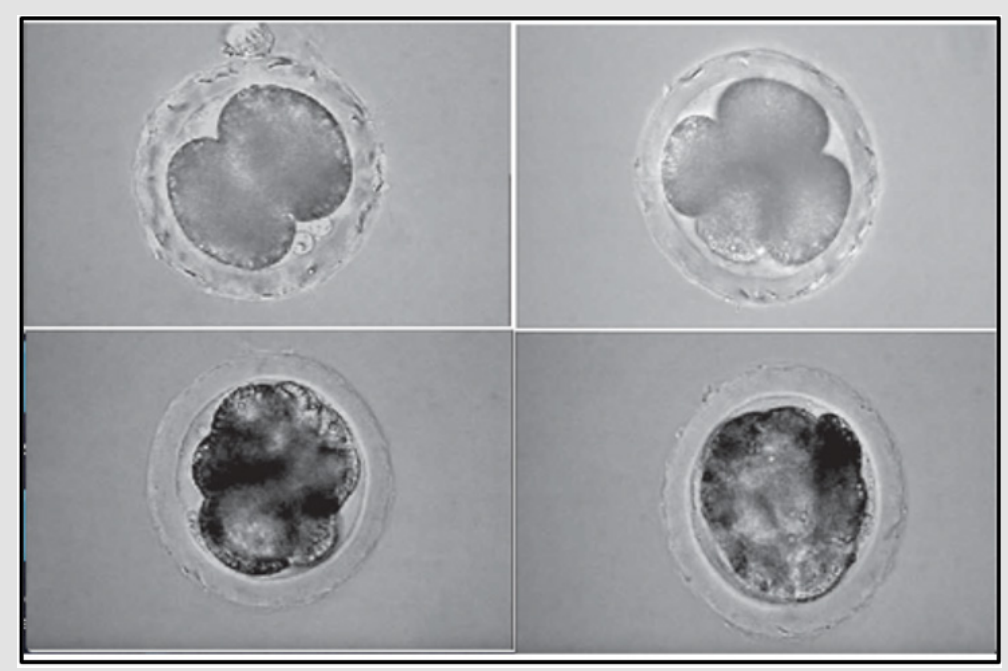

Figure 4: Different stages of development of a swine embryo from cleavage to blastocyst (adapted from [21]).

\section{Proceeding}

Referring to [21,22], after the gametes coincide for $6 \mathrm{~h}$, the zygotes are washed three times and transferred to the culture medium. Embryo culture medium contains different levels of energy sources such as glucose, calcium, lactate, pyruvate and vitamins [3].One of the media used is NCSU37 and contains $0.4 \%$ BSA [22].Supplemented with $0.17 \mathrm{mM}$ sodium pyruvate and $2.73 \mathrm{mM}$ sodium lactate, the zygote remains qui until day 2 post fertilization. From day 2 to day 7 the zygotes remain in a culture medium supplemented with 5.55mM D-glucose.

\section{Rating Criteria}

After IVF there are different criteria for assessing porcine embryos: developmental status, integrity of the zona pellucida, delimitation and uniformity of blastomeres and presence of perivitelline space [23].

\section{PIVES limitations}

This biotechnique has several limiting factors, such as low embryonic development capacity up to the blastocyst stage, difficulty in achieving cytoplasmic maturation in oocytes, high polyspermy rate and reduced viable embryo culture rate [4].

\section{Low Embryonic Development Capacity}

In accordance with [24], the in vitro development of the swine embryo to 4 cells presents difficulties. However, there are methods that allow us to work around this problem, causing the complete development of embryos from the stage of a cell to the blastocyst stage. By changing the culture media, adding taurine and hypotaurine increase the degree of embryonic development in vitro. According to [25], 90\% of the 2-cell embryos singled out and overcame the 4-cell block and 85\% evolved to blastocyst using the culture medium with taurine and hypotaurine.

\section{Difficulty in Achieving Cytoplasmic Maturation}

Conforming to [4], the medium used in IVM may be relevant in the failure of embryonic development, since it is at this stage that the oocyte acquires skills to progress. However, it is known that it is necessary to lower the concentration of sodium chloride or supplement the maturation medium with cysteine for an improvement in the rate of embryonic development.

\section{Polyspermy}

As reported by [26], polyspermy is defined as the penetration of more than one sperm into the oocyte during fertilization. It is observed in IVF when more than two pronuclei are present within the oocyte or the presence of several fused sperm. This pathology causes premature death of the embryo. Polyspermy, both in vivo and in vitro, occurs most often in swine [9].In swine, sperm washing is done by centrifugation in basic media containing enabling factors such as calcium and bicarbonate supplemented with BSA and caffeine induce rapid increase of sperm contact with oocyte. According to [13], this is one reason why there is such a high polyspermy rate in swine. Mechanisms have been developed to block polyspermy in mammals in the oviduct, preventing largescale arrival of sperm in the vicinity of the oocyte. And in the oocyte, including changes in the membrane and the zona pellucida where the zona pellucida hardens before fertilization [27].

\section{Reduced Viable Embryo Culture Rate}

The in vitro embryo culture rate shows lower viability compared to in vivo production. According to [21], the total number 
of blastocysts varies between 30 and 38 on day 6 after in vitro and in vivo fertilization rises to 74 . In accordance with [17], the main cause of the low culture rate of viable embryos is due to the high polyspermy rate that causes poor quality oocytes. According to a study by him, for low quality oocytes, the rate of blastocyst stage embryos increases after a $1.5 \mathrm{~h}$ pre-incubation of semen. However, for high quality embryos this doesn't happen. There are no changes in the rate of blastocyst stage embryos. Another study by [28], proposes that the combination of oviduct and heparin fluid improves the production of monospermic zygotes during IVF in swine.

\section{PIVES Applications}

Overall, there have been developments in the methodology of in vitro embryo production, in order to maximize genetic gain and animal production at low cost. Producing in vitro embryos on a commercial scale increases the benefits of artificial insemination, due to its primary role in intergenerational genetic development, which meets the needs of each breeding program [29,30]. Reported by [9], this biotechnology is used for studies related to fertilization, sperm function, oocyte maturation, sperm capacitation systems, mechanisms inherent in the interaction between gametes and in the study of the signals that intervene in the processes of development and differentiation embryo. The scientific community has developed potential interest in the use of porcine embryos in biomedicine. Since they have physiological, genetic and anatomical similarities to humans, in vitro produced embryos and some in vivo embryos are used in research to acquire stem cells or to produce transgenic animals in order to use their organs for transplantation [13].

\section{Conclusion}

Despite efforts by the scientific community to make progress in this technique, significant challenges remain.

\section{Competing Interests}

The authors declare that they have no competing interests.

\section{Acknowledgement}

"This project was financed in $85 \%$ by FEDER and in 15\% with regional funds through the Azores 2020 Operational Program (Operational Program Azores 2020), in scope of the project «CRYOTEC - ACORES-01-0145-FEDER-000092."

\section{References}

1. Grupen C (2014) The evolution of porcine embryo in vitro production. Theriogenology 81: 24-37.

2. Fowler K, Mandwala A, Griffin D, Walling G, Harvey S (2018) The production of pig preimplantation embryos in vitro: Current progress and future prospects. Reproductive biology 18: 203-211.

3. Motta L, Chaves D, Bhat $\mathrm{H}$ (2018) In vitro embryo production in the pig Reproduction biotechnology in farm animals. 8: 200-222.
4. Serret C, Júnior T, Deschamp J, Corrêa M (2007) In vitro production of swine embryos. R Bras Agrociência Pelotas 13(3): 285-289.

5. Frare AL, Pontili AD, Jacobovski DA, Teixeira E, Malherbi G, et al. (2013) Ciclo estral dos suínos. Faculdade Assis Gurgacz, Cascavel, Paraná, Brazil.

6. Monteiro M (1999) Aspetos reprodutivos de fêmeas da raça suína alentejana. Dissertação de mestrado em produção animal. Universidade técnica de Lisboa. Faculdade de medicina veterinária, Portugal.

7. Vacquier V, Hirohashi N (2004) Development of Sea Urchins, Ascidians, and other invertebrate deuterostomes: Experimental Approaches. Methods in cell biology. 74: 523-544.

8. Coffey R, Parker G, Laurent K (1997) Manipulation of the estrous cycle in swine. Cooperative extension service. College of Agriculture, University of Kentucky, USA.

9. Oberlender G, López R, De Ondiz Sánchez A, Vieira L, Pereira M, et al. (2016) In vitro fertilization of porcine oocytes is affected by spermatic coincubation time. Pesquisa Veterinária Brasileira 36(1): 58-64.

10. Valadão L (2019) Efeito do antioxidante alfa-tocoferol na taxa de maturação de ovócitos bovinos. Dissertação de mestrado em engenharia zootécnica. Universidade dos Açores.

11. Marquant Le Guienne B (1998) Petit atlas de l'ovocyte. Elevage et Insémination $288: 24-30$.

12. Yuan Y, Krisher R (2012) In vitro maturation (IVM) of porcine oocytes. Wai-Yee and Le Ann Blomberg (Eds.)., Germline Development: Methods and Protocols, Methods in Molecular Biology. Vol. 825.

13. Romar R, Cánovas S, Matás C, Gadea J, Coy P (2019) Pig in vitro fertilization: Where are we and where do we go? Theriogenology. 137: 113-121.

14. Allworth A, Albertini D (1993) Meiotic maturation in cultured bovine oocytes is accompanied by remodeling of the cumulus cell cytoskeleton. Developmental biology 158: 101-112.

15. Sirard M (2001) Resumption of meiosis: mechanism involved in meiotic progression and its relation with developmental competence. Theriogenology. 55: 1241-1254.

16. Ferreira E, Vireque A, Adona P, Meirelles F, Ferriari R, et al. (2009) Cytoplasmatic maturation of bovine oocytes: Structural and biochemical modifications and acquisition of developmental competence. Theriogenology 71: 836-848.

17. Gil M, Ruiz M, Cuell C, Vazquez J, Roca J, et al. (2004) Influence of sperm: oocyte ratio during in vitro fertilization of in vitro matured cumulusintact pig oocytes on fertilization parameters and embryo development. Theriogenology 61: 551-560.

18. Vacquier V, Hirohashi N (2004) Development of Sea Urchins, Ascidians, and other invertebrate deuterostomes: Experimental Approaches. Methods in cell biology 74: 523-544.

19. Cole L (2016) Sperm activation, fertilization, morula, blastocyst formation, and twinning. Biology of life: 143-150.

20. Okamoto A, Ikeda M, Kaneko A, Kishida C, Masayuki S, et al. (2016) The novel pig in vitro maturation system to improve developmental competence of oocytes derived from atretic non vascularized follicles. Biology of reproduction 95(4): 7.

21. Rath D, Long CR, Dobrinsky JR, Welch GR, Schreier LL, et al. (1999) In vitro production of sexed embryos for gender preselection: high-speed sorting of X-chromosome bearing sperm to procedure pigs after embryo transfer. J Anim Sci 77: 3346-3352.

22. Serret C, Júnior T, Deschamp J, Corrêa M (2007) In vitro production of swine embryos. R. Bras. Agrociência. Pelotas. 13(3): 285-289.

23. Reed ML, Illera MJ, Petters RM (1992) In vitro culture of pig embryos. Theriogenelogy. 37: 95-109.

24. Brussow K, Torner H, Kanitz W, Rátky J (2000) In vitro technologies related to pig embryo transfer. Reprod Nutr Dev 40: 469-480. 
25. Wang WH, Day DN, Wu GM (2003) How does polyspermy happen in mammalian oocytes? Micr Res Tech 61: 335-341.

26. Coy P, Avilés M (2010) What controls polyspermy in mammals, the oviduct or the oocyte? Bio Rev 85: 593-605.

27. Katska-Ksiazkiewicz L (2006) Pig embryo production by in vitro maturation and fertilization of ovarian oocytes. A review. Journal of Animal and feed sciences. 15: 525-542.

28. Brogni C, Ohlweilerd L, Klein N, Mezzalira J, Cristani J, et al. (2016) Preincubation of porcine semen reduces the incidence of polyspermy on

ISSN: 2574-1241

DOI: $10.26717 /$ BJSTR.2020.26.004337

Valadão L. Biomed J Sci \& Tech Res

(C) This work is licensed under Creative

Submission Link: https://biomedres.us/submit-manuscript.php embryos derived from low quality oocytes. Ciência Rural. Santa Maria 46(6): 1113-1118.

29. Batista R, Moro L, Corbin E, Alminana C, Souza-Fabjan J, et al. (2016) Combination of oviduct fluid and heparin to improve monospermic zygotes production during porcine in vitro fertilization. Theriogenology 86: 495-502.

30. Rumpf R (2007) Methodological advances on in vitro embryo production. R Bras Zootec 36: 229-233. 